\title{
Políticas y lugares de la memoria: una aproximación a las estrategias de representación y transmisión del pasado reciente en el Espacio Mansión Seré, Municipio de Morón
}

\author{
Gabriel E. Margiotta \\ Universidad de Buenos Aires, Argentina \\ gemargiotta@gmail.com
}

\section{Resumen:}

En este trabajo nos proponemos realizar una aproximación a las estrategias de transmisión del pasado reciente en el Espacio Mansión Seré (EMS), ubicado dentro del polideportivo municipal Gorki-Grana, en el Municipio de Morón, provincia de Buenos Aires. Dicho espacio constituye una referencia de importancia en lo que hace a las políticas públicas sobre derechos humanos y memoria tanto a nivel provincial como nacional. En esta aproximación, nos interesa indagar en algunos de los modos en que la investigación arqueo-antropológica es utilizada para construir un relato y una narrativa sobre la historia del lugar. Centrándonos en el período 2013-2016, el foco estará puesto en cómo esta narrativa se materializa a través de los modos en que los testimonios, objetos y fotografías del archivo documental se articulan, se traman y dialogan entre sí en el espacio y en el recorrido del EMS. La hipótesis es que, haciendo uso de las huellas del pasado, en diferentes dispositivos instalados en el espacio se intenta propiciar la imaginación como medio para la reflexión sobre la historia del lugar.

Palabras clave: Mansión Seré, Políticas públicas, Lugares de memoria, Imaginación.

\section{INTRODUCCIÓN}

Una serie de preguntas suelen plantearse para el debate en torno a la representabilidad/ irrepresentabilidad y lo decible/indecible sobre el horror de las catástrofes sociales a la hora de recordar y de transmitir el pasado sobre ellas. Entre ellas podemos encontrar: ¿De qué modos debe representarse el pasado para la memoria histórica de una sociedad? ¿Es posible representar el horror? En ese caso, ¿es la representación del horror un modo de visibilizarlo y darlo a conocer o puede habilitar la apología y/o la banalización del mismo?

En relación al Holocausto ${ }^{1}$, Regine Robin (2014) plantea que existe una dificultad en la transmisión del pasado que está dada por un lado, por la banalización de la violencia en los medios y por otro, por un exceso de representación que ha caído en lo trillado y que produce la saturación de la memoria. Para la autora esta saturación implica también una sacralización de los testimonios, que cristalizan el horror y no permiten complejizar el acontecimiento.

En este trabajo proponemos realizar una aproximación a las estrategias de transmisión del pasado reciente y los dispositivos memoriales en el Espacio Mansión Seré (EMS), ubicado dentro del polideportivo municipal Gorki-Grana, en el municipio de Morón de la provincia de Buenos Aires. El objetivo es indagar en los modos en que la investigación arqueo-antropológica realizada allí es utilizada para construir un relato y una narrativa sobre la historia del lugar. En este sentido, el foco estará puesto en cómo esta narrativa se materializa a través de los modos en que los testimonios, objetos y fotografías del archivo documental producido en la investigación se articulan, se traman y dialogan entre sí en el espacio y en el recorrido del Espacio Mansión Seré. Las principales fuentes de esta indagación son entrevistas, material de archivo y registros de campo producidos en el período 2013-2017, marco temporal en el que centraremos el análisis y que toma como punto de partida el año en que se inaugura el Espacio Mansión Seré: Centro de Investigación e Interpretación de Nuestra Historia Reciente. En primer lugar, describiremos los modos en que la ausencia material de Mansión Seré, destruida en 1985, es pensada como punto de partida para la construcción del relato sobre la historia del lugar. En un segundo momento, describiremos qué tipos de objetos y materiales del archivo documental producido en la investigación arqueológica del sitio son utilizados en el recorrido por 
el espacio. Finalmente, analizaremos dos dispositivos memoriales instalados en el espacio como estrategias de transmisión y sus potencialidades. La hipótesis es que estos intentan propiciar la imaginación como medio para la reflexión sobre el pasado. En este sentido, y como analizaremos más adelante, el recorrido del EMS está orientado a construir un relato abierto e inacabado por medio de la presentificación de escenas del pasado en las que se traman testimonios, hallazgos arqueológicos y fotografías de manera que intentan suscitar una reconstrucción del pasado por parte del visitante.

\section{El Espacio Mansión Seré}

El EMS se emplaza sobre los cimientos de lo que fue la Mansión Seré, una edificación construida a principios del siglo XIX por una familia francesa de gran fortuna que se dedicaba a la actividad ganadera. En 1949 el predio y la mansión fueron adquiridos por la Municipalidad de Buenos Aires quien la destinó a la realización de actividades del Instituto de Previsión Social. En el año 1976, iniciada la última dictadura militar en Argentina ${ }^{2}$, el predio fue cedido en comodato a la Fuerza Aérea, quien entre 1977 y 1978 utilizó el edificio como centro clandestino de detención (CCD) denominado "Atila". El mismo dejó de funcionar luego de la fuga de cuatro detenidos y la mansión destruida a causa de un incendio. En 1985, ya en democracia, el predio se destinó a la construcción del polideportivo Gorki-Grana, por lo que se demolieron los restos de la mansión y sobre sus cimientos se emplazó una cancha de fútbol. En el año 2000, durante la gestión de Martín Sabbatella, el Municipio de Morón y la Asociación Seré (asociación de derechos humanos integrada por familiares de víctimas, ex detenidos y vecinos de Morón) convocaron a un equipo de investigación compuesto inicialmente por estudiantes de arqueología y antropología de la Facultad de Filosofía y Letras de la Universidad de Buenos Aires para la realización de una excavación arqueológica que contribuyera a la búsqueda de evidencias sobre el funcionamiento del centro clandestino y convertirlo en un espacio dedicado a la memoria. Años más tarde, estas evidencias serían utilizadas en el marco de los juicios abiertos por crímenes de lesa humanidad durante la dictadura cívico-militar. ${ }^{3}$ De esta manera surgió en el año 2002 el Proyecto Arqueológico-Antropológico Mansión Seré, cuyo equipo interdisciplinario de trabajo llegó a estar conformado por más de treinta investigadores. El Proyecto representó una de las primeras experiencias de las políticas públicas de memoria de oficialización de sitios de memoria sobre el terrorismo de Estado en Argentina ${ }^{4}$ que se profundizarían a partir del año 2004 a nivel nacional impulsadas por el gobierno de Néstor Kirchner. ${ }^{5}$

En el año 2013 se terminó de construir un cerramiento sobre la excavación de los cimientos de la mansión y el sitio pasó a denominarse Espacio Mansión Seré: Centro de Investigación e Interpretación de Nuestra Historia Reciente. ${ }^{6}$ El mismo está situado dentro del predio que corresponde al polideportivo Gorki-Grana. Los cimientos de la mansión se encuentran techados y rodeados por un conjunto de pasarelas que permiten recorrerlos y observarlos. Las pasarelas, además, cuentan con un cerramiento de vidrio que posee fotografías traslúcidas de los detenidos-desaparecidos en el municipio de Morón. Estas pasarelas delimitan y separan el sitio arqueológico de un patio recreativo y un laboratorio en el que se desarrollan actividades de investigación y de conservación arqueológica. 
FIGURA $\mathrm{N}^{\circ} 1 \mathrm{Y} \mathrm{N}^{\circ} 2$

Vistas interna y externa del EMS. Fotografías: Registro de campo 26-04-14

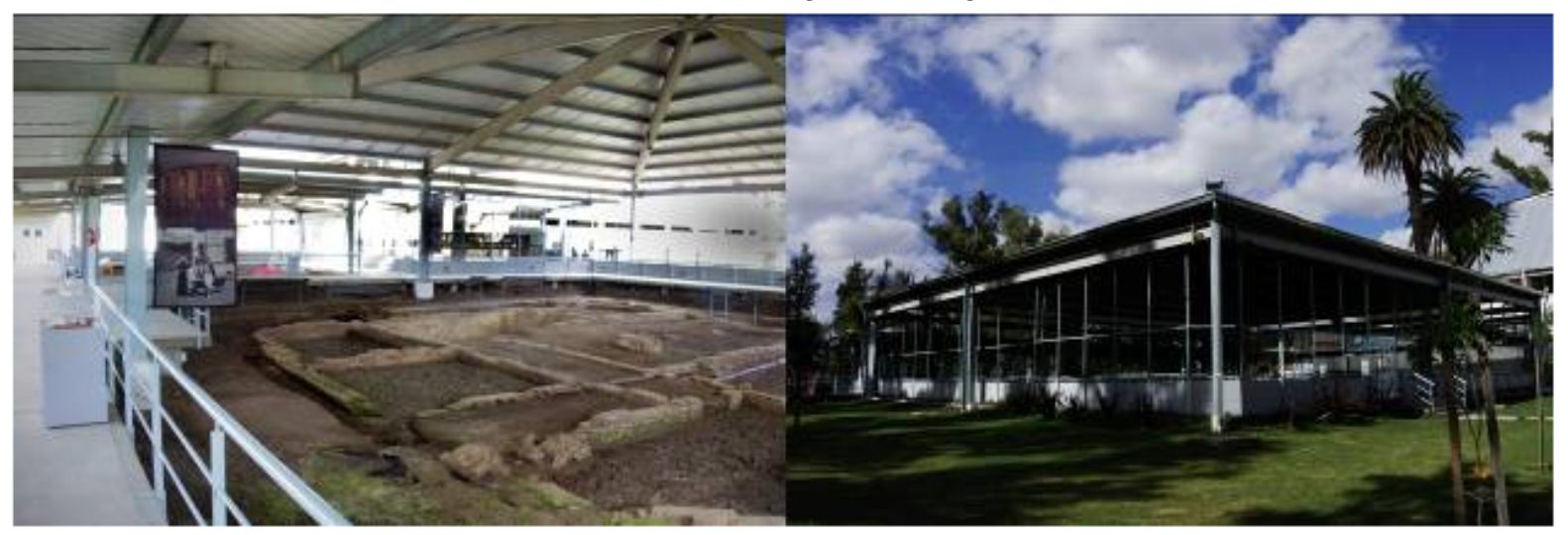

\section{LA “AUSENCIA” COMO PUNTO DE PARTIDA}

Una vez recuperado el espacio donde se encontraba la Mansión Seré, comenzaron en el año 2002 las excavaciones en los cimientos del edificio demolido en 1985. Esta propuesta fue el resultado de un convenio entre organismos de DDHH regionales y el Municipio de Morón. Se convocó de manera privada a un grupo de arqueólogos y antropólogos de la Universidad de Buenos Aires para realizar la investigación que tenía como objetivos "efectuar trabajos de recuperación documental y testimonial tendientes a la reconstrucción de la memoria y transmisión de la experiencia entre generaciones acerca de la historia de lo ocurrido durante el terrorismo de Estado". 7 Como señala San Julián (2014) si bien en una etapa inicial la investigación se dedicó a la ubicación y rescate de las estructuras de la mansión y los objetos que se hallaran asociados, así como el relevamiento de documentos y testimonios de ex detenidos, familiares de desaparecidos y vecinos del barrio, con el tiempo los objetivos del proyecto se ampliaron hacia el registro de historias de vida, la conformación de un Archivo Documental y una propuesta museológica para implementar en el sitio cuando finalizaran las excavaciones. Este conjunto de propuestas involucró la participación de un grupo de investigadores graduados y estudiantes de carreras como Antropología y Arqueología, Historia, Ciencias de la Comunicación, Conservación y Museología que conformaría luego el Grupo Arqueológico Antropológico Memoria e Identidad (GAAMI). Algunos de los integrantes de este grupo se convirtieron con el tiempo en las personas encargadas de la gestión y realización de actividades en el EMS. ${ }^{8}$

De la misma manera que en el Ex CCD "Club atlético", en Mansión Seré fue necesario realizar una investigación arqueológica que reconstruyera no sólo el funcionamiento y el uso del edificio por parte de los militares sino también su arquitectura y características edilicias, ya que habían sido demolidos para dar lugar a la construcción de la autopista 25 de mayo en el caso del primero y para construir una cancha de fútbol en el caso del segundo. En este sentido, un miembro del equipo de investigación y conservación del EMS planteaba una diferencia con otros ex CCD como la ESMA y "Olimpo":

Acá es diferente, por eso, cuando uno está inmerso en esa disputa por imponer un sentido, de qué es lo que sucedió en este espacio, de qué es lo que sucedió en el país en esa época, te encontrás con cierta “ausencia” podríamos decir, en principio. No tanto ahora, ¡mucho más cuando llegamos acá y había una cancha de fútbol! ¿Cómo reconstruís o cómo tratás de dar cuenta de ese relato, ese sentido que vos querés dar a comunicar si teóricamente no tenés nada? Teóricamente. Después empezás a tener, porque empezás a trabajar y empezás a encontrar algunas estructuras. Pero bueno siempre es un relato más dificultoso si se quiere, vos tenés que hablar de algo que no existe. Inclusive hoy mismo hay gente que viene acá y piensa que la mansión todavía está. 9 
La "ausencia" de materialidad es así presentada como un punto de partida doble, por un lado, el de la investigación en la que se complementarían el trabajo arqueológico y el antropológico y, por otro, el de la reconstrucción del relato con el que se quiere dar cuenta de lo sucedido en Mansión Seré.

Según los autores que analizan y describen el proceso de la investigación en Mansión Seré, se utilizaron "cuatro líneas de evidencia: la fotografía, los objetos reclamados de la mansión, la cultura material y la memoria oral" (Di Vruno et al, 2008; Doval et al, 2010). El trabajo de reconstrucción de los planos de la mansión se realizó, por un lado, mediante la excavación arqueológica, a partir de la cual se confeccionó un plano tentativo de la planta baja, mientras que el plano de la planta alta fue realizado empleando un archivo fotográfico, croquis y testimonios de ex detenidos desaparecidos y vecinos (Di Vruno et al, 2008; Doval et al 2010). El archivo fotográfico empleado, sobre el que volveremos más adelante, es el archivo de fotografías históricas que se encuentra dentro del Archivo Documental de la Dirección de DDHH del municipio y se compone de fotografías donadas durante el transcurso de la investigación por personas que habían visitado el predio en diferentes contextos. La información proporcionada por los testimonios orales y los croquis realizados por ex detenidos desaparecidos generaba una serie de vacíos y contradicciones que fueron posibles superar al cruzar estos datos con los provistos por las fotografías pertenecientes a dicho archivo:

Se organizó la información del archivo fotográfico construyendo una base de datos donde cada fotografía fue denominada por un único número y ubicada espacialmente, identificando el sector desde donde fue tomada, los sectores que retrataban, sus características visibles y su contextualización temporal. Este trabajo permitió ubicar las aberturas externas (puertas y ventanas) a sus distancias relativas, las aberturas internas, la chimenea y ratificar la ubicación de la escalera principal, la cantidad de recintos y su tamaño. Además, se pudieron observar características como superposición de capas de pinturas, cortes de muros y su relación con determinados objetos arqueológicos y testimonios orales y escritos. (Doval et al. 2010:217)

Si bien los resultados de la investigación proporcionaron datos sobre los usos de la mansión a lo largo de su historia y sobre todo sobre el período en que fue utilizada como CCD hasta el punto en que fue posible hacer una reconstrucción de los planos de la casa, a la hora de contar la historia del lugar la decisión ha sido la de no reconstruir de manera física ninguno de los espacios. Aquí, la "ausencia" opera como punto de partida para el relato de la historia del lugar en el sentido de que esta decisión es entendida también como un modo de hacer visible esa ausencia de materialidad y como posibilidad de dotarla de sentido histórico. En palabras de uno de los miembros del equipo:

El hecho de que la mansión esté destruida es significativo en sí mismo y muchas veces el hecho de entrar y encontrarte con un pozo [arqueológico] y una serie de ladrillos dispara en una pregunta que es ‘'y por qué la destruyeron? ¿La van a reconstruir?’ Y eso ya es el disparador para toda una discusión, una discusión en tanto lo que fue "El Proceso" como lo que fue después y todo lo que vino después [...]. La destrucción, todo esto de tapado, de haber puesto una cancha de fútbol encima y demás nos está contando un pedazo de la historia importante $[\ldots]^{10}$

De esta manera, la ausencia de materialidad es utilizada para dar cuenta de una ausencia simbólica del reconocimiento y conmemoración oficial de los crímenes cometidos allí hasta el momento en que Seré es refuncionalizado como sitio de memoria.

Si bien el punto de partida es la "ausencia", esta aparece como contrapartida de una "presencia" de materialidad que es producto de la investigación arqueoantropológica y sobre la cual se apoya el relato sobre el pasado del lugar. Es a partir de la ausencia/presencia de materialidad que es posible construir sentidos para la transmisión del pasado. Siguiendo el planteo de Luciana Messina en que "un espacio material no tiene sentido en sí mismo, a menos que sea marcado por un sujeto como lugar significativo para narrar su historia" (2011:12), entendemos que es la práctica de investigación arqueológica la que intenta inscribir los sentidos sobre cómo debe interpretarse la materialidad. En este sentido, Adriana D'Ottavio, analizando las practicas arqueológicas de interpretación de materialidades en ex CCD devenidos en sitios de memoria, plantea que en el intento de la arqueología por establecer certezas, lo ausente y determina límites a las interpretaciones sobre la materialidad presente ya que es 
(...) una de las particularidades de la interpretación de ruinas que, como materialidades inestables, cambiantes, con capas temporales yuxtapuestas, presentan un carácter ambiguo que no siempre puede neutralizarse. La práctica de la arqueología y la conservación funda un régimen de inteligibilidad que hace que las paredes de los ex CCDTyE cuenten historias, pero que a la vez muestra las opacidades e incertidumbres en las mismas y pone de manifiesto que todos los sentidos son inestables, en tanto pueden ponerse en duda por nuevos hallazgos o testimonios. (D'Ottavio, 2017: 165)

Más adelante analizaremos dos de las estrategias con las que el "relato" sobre la existencia del edificio y sobre el funcionamiento del CCD es transmitido, así como el modo en que la inestabilidad de sus sentidos entra en relación con la ausencia/presencia de materialidad.

\section{MEMORIA ORAL, FOTOGRAFÍAS Y MATERIALES ARQUEOLÓGICOS}

Los dispositivos memoriales del recorrido del EMS que analizaremos en este trabajo poseen materiales pertenecientes al Archivo Documental de la Dirección de Derechos Humanos del Municipio de Morón y materiales arqueológicos como fragmentos de baldosas, paredes y otros elementos constructivos de la casa. Ambos tipos de recursos son el producto de la investigación arqueo-antropológica que implicó, además de la excavación, una serie de entrevistas a ex detenidos desaparecidos en "Atila", a descendientes de la familia Seré y vecinos del barrio del predio. Tanto la excavación como el archivo no están cerrados, por lo que siguen abiertos a recibir e incorporar nuevos materiales. Las entrevistas pasaron a constituir la memoria oral del archivo y mediante ellas se obtuvieron, además, una gran cantidad de fotografías históricas que fueron claves en la reconstrucción del edificio y materiales del mismo sustraídos del lugar durante sus años de abandono.

El Archivo Documental contiene un corpus de memoria oral que incluye charlas informales y entrevistas extensas. Por otro lado, un grupo de objetos sustraídos durante los años de abandono del edificio que han sido donados por los vecinos. Hay que tener en cuenta el valor simbólico que estos objetos poseían para quienes los donaron ya que en muchos casos constituyen recuerdos personales sobre el lugar:

El análisis de la memoria oral y de los relatos que acompañaron la donación de cada objeto nos permitió dilucidar que existieron tres causalidades que motivaron estas acciones: económicas, simbólicas y vandálicas. Además, la materialidad de un objeto pudo funcionar como un disparador de memorias y recuerdos vinculados a ese espacio desde la relación que ligó a cada individuo con el sitio (la infancia, el repudio, el barrio, etc.). En este sentido, la donación implicó un desprendimiento de un objeto con una alta significación para el individuo (...) (Doval Y Giorno, 2010:46).

Como mencionamos anteriormente, el archivo de fotografías históricas ha sido de gran importancia y es muy vasto. $\mathrm{Al}$ momento en que se realizó está indagación ${ }^{11}$ contenía 129 imágenes que abarcan un lapso de más de 60 años. Se compone por un lado, de 14 fotografías de la década del ' 30 pertenecientes al álbum familiar de la familia Seré, 105 fotografías que representan el período 1970 - 1985 donadas por vecinos y 10 imágenes tomadas en 1984 en el marco del juicio a las Juntas Militares durante el reconocimiento del CCD $\mathrm{u}$ otras instancias del proceso judicial, algunas de ellas donadas por ex detenidos desaparecidos.

Las fotografías de la familia Seré corresponden a los recuerdos familiares del momento en que todavía la familia estaba en posesión del predio en la década del '30. La quinta de los Seré, en su origen, poseía sesenta hectáreas que habían sido adquiridas por Jean Seré, un terrateniente vasco francés, a mediados del siglo XIX. Allí, una de sus hijas, Leocadia Seré edificó la mansión en el 1900, utilizada como casco de estancia. ${ }^{12}$ Más tarde, los golpes de la crisis de 1930 dieron origen, mediante loteos masivos, a lo que se conoce actualmente como Barrio Seré. Son por lo tanto fotografías que corresponden a un momento de acceso restringido y privado al predio y a la mansión, pero que dan cuenta del terreno donde hoy se emplaza el barrio que rodea el polideportivo Gorki-Grana (Doval, 2011; Fabri, 2016).

Las fotografías de vecinos (Figura $\mathrm{N}^{\circ} 3$ ) se concentran en los años '70-'80 porque es el momento de fácil acceso al predio debido a su abandono y también porque es un período de proliferación de cámaras fotográficas. En este sentido, se encuentran fotografías que registran sectores de la casa y su deterioro, así 
como también las pintadas y grafitis que se le van realizando en esos años. Además de estas, en algunas de ellas aparecen personas posando con fines artísticos o expresivos, pero son en general fotografías pertenecientes a álbumes familiares de vecinos de Mansión Seré.

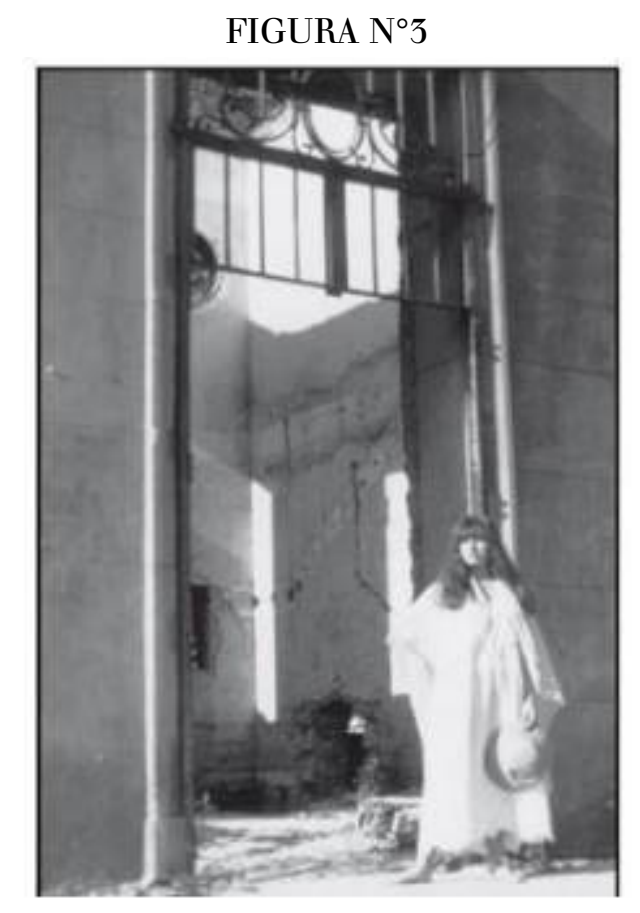

Doval et al. (2010)

Es así que estos dos primeros grupos están integrados por fotografías familiares. Este tipo de fotografías además de cumplir una función en la memoria y narrativa familiar, resaltando algunos momentos particulares de la vida familiar, también constituyen, quizás involuntariamente, documentos y testimonios del pasado. Agustina Triquell resalta que:

La fotografía doméstica ingresa así en el dominio público, se instala en la narrativa de los museos, ilustra y da cuenta de modos de vida de tiempos anteriores. Las imágenes que el álbum contiene se encuentran de este modo marcadas por la referencia a un espacio social más amplio, que desborda lo biográfico específico de los allí retratados y pasa a dar cuenta de identificaciones ideológicas, históricas y estéticas (Triquell, 2012:19)

Es esta potencialidad la que entra en juego en el uso metodológico de las fotografías en la tarea de la reconstrucción de los planos del edificio a partir del registro de sus detalles.

El último constituye un grupo de fotografías de registro documental que corresponden a la visita de la Comisión Nacional sobre la Desaparición de Personas (CONADEP) ${ }^{13}$ en las que se pueden ver un grupo de personas recorriendo el edificio en su labor de reconocimiento. Son fotografías que responden a un uso fotoperiodístico. Cora Gamarnik (2015) señala la importancia del fotoperiodismo en los primeros años del retorno de la democracia. En un contexto en el que el repudio popular a la dictadura crecía a medida que se revelaba el horror de los crímenes, el fotoperiodismo contribuyó a evidenciar lo que había sido el aparato represivo genocida. En este sentido, "la prensa amplificaba la denuncia y distintos actores sociales sumaban su voz pidiendo esclarecer e investigar lo sucedido. De esta forma, el fotógrafo resultaba ser el primer eslabón de una cadena de hechos." Las fotografías de la visita de la CONADEP tienen así la importancia de ser uno de los primeros espacios de exposición pública de los crímenes cometidos en "Atila" ${ }^{14}$ y son las encargadas de transmitir y documentar uno de los primeros reconocimientos oficiales del CCD. 
Hasta el momento de su integración al Archivo Documental, estas fotografías fueron produciéndose y guardándose durante años, así como los restos de la edificación sustraídos por vecinos. Pero mediante la investigación, las fotografías pertenecientes a un archivo familiar o las que constituyen documentos personales empiezan a entramarse con otras fotografías y otros objetos materiales y disparan recuerdos en los vecinos, memorias que van conformando un archivo oral. Todas estas comienzan a dialogar entre sí mediante la textura que implica la conformación del Archivo Documental. En este entramado, se activan otros sentidos sobre la huella que las imágenes portan y que los objetos constituyen, aquellos sentidos que hablan sobre la historia, los usos, la cronología y los detalles edilicios de la mansión. Es el archivo quien hace hablar a sus fotografías sobre la historia de Mansión Seré, y en ese hablar, devienen testigos. Me interesa resaltar la potencialidad de estas imágenes, que en su producción van generando memorias barriales sobre Seré y cuyos sentidos se multiplican a partir de la recuperación del predio y el comienzo de la política de memoria sobre el EMS.

Así como los testimonios y la memoria oral, el archivo también es siempre fragmentario e incompleto. En palabras de Didi-Huberman:

[...] Cada vez que intentamos construir una interpretación histórica [...] debemos tener cuidado de no identificar el archivo del que disponemos, por proliferante que sea, con los hechos y los gestos de un mundo del que no nos entrega más que algunos vestigios. Lo propio del archivo es la laguna, su naturaleza agujereada (2007, pp. 15-16).

\section{DISPOSITIVOS EN EL ESPACIO}

En este apartado nos proponemos indagar en las estrategias de transmisión del pasado en Mansión Seré que, como señalamos anteriormente, involucran la instalación de dispositivos memoriales en el recorrido por el espacio. Para este análisis es necesario entonces definir a qué se refiere el concepto de dispositivo y en qué modos entendemos que se configuran como memoriales.

El concepto de dispositivo ha sido utilizado por Michel Foucault a lo largo de su obra pero sin brindar sobre él una definición precisa. En este sentido, nos interesa recuperar la sistematización que han realizado Gilles Deleuze (1990) y Giorgio Agamben (2011) sobre los sentidos e implicancias con las que el término es usado por Foucault. Según Deleuze los dispositivos se configuran mediante una serie de líneas o dimensiones. En primer lugar, líneas de visibilidad y enunciación que hacen de los dispositivos "máquinas para hacer ver y hacer hablar", es decir, determinan regímenes de lo visible y de lo enunciable. Además, estos regímenes están atravesados por líneas de fuerza que rectifican y ordenan a las dos anteriores y que son a la vez invisibles e indecibles. Estas últimas se corresponden con la dimensión del poder y el saber. Por último, lo propio de los dispositivos es una serie de líneas que se caracterizan por la producción de subjetividad.

Por otro lado, Agamben señala que el dispositivo "se trata de un conjunto heterogéneo que incluye virtualmente cada cosa, sea discursiva o no: discursos, instituciones, edificios, leyes, medidas policíacas, proposiciones filosóficas. El dispositivo, tomado en sí mismo, es la red que se tiende entre estos elementos" (Agamben, 2011:250). De esta manera, para el pensador italiano un dispositivo es "todo aquello que tiene, de una manera u otra, la capacidad de capturar, orientar, determinar, interceptar, modelar, controlar y asegurar los gestos, las conductas, las opiniones y los discursos de los seres vivos" (Agamben, 2011: 257)

En base a estas conceptualizaciones, consideramos dispositivos memoriales a aquellos elementos materiales y discursivos que, como artefactos y/o soportes instalados en el espacio y producidos desde la política pública de memoria, configuran narrativas y orientan ciertas representaciones y modos de recordar el pasado de Mansión Seré.

Proponemos, además, pensar las estrategias de transmisión y de representación del pasado en el Espacio Mansión Seré en relación a la imaginación y a los vínculos que existen entre la imagen y la memoria. En este sentido, Ricoeur (2004) nos presenta a la memoria y la imaginación como implicadas mutuamente desde los 
comienzos de la filosofía occidental. Según el autor, Platón parte del pensamiento sobre la representación de una cosa ausente y plantea implícitamente que la problemática de la imaginación envuelve a la de la memoria; mientras que Aristóteles piensa en la representación de una cosa percibida, aprendida o adquirida anteriormente para plantear que la problemática del recuerdo incluye la de la imagen (Ricoeur, 2004). Por lo tanto la imaginación y la memoria son impensables una sin la otra, indiscernibles:

La pregunta embarazosa es la siguiente: ¿es el recuerdo una especie de imagen? Y, si sí, ¿cuál? Y si resultara posible explicar, mediante el análisis eidético apropiado, la diferencia esencial entre imagen y recuerdo, ¿cómo esclarecer su imbricación, incluso su confusión, no sólo en el plano del lenguaje, sino también en el de la experiencia viva?: ¿no se habla de recuerdoimagen, incluso del recuerdo como de una imagen que uno se hace del pasado? (Ricoeur, 2004:67)

Por otro lado, para pensar el lugar que ocupa la imaginación en los recorridos de museos y de qué manera estudiarla, Marianne Achiam plantea que la misma implica "la capacidad esencial que nos permite formar una representación mental de algo" (Achiam, 2016:90) y que "está involucrada en la generación de nuevo conocimiento porque nos permite crear construcciones mentales basadas en la observación, el conocimiento previo y aquello que está ausente" (Achiam, 2016:90). ${ }^{15}$ Esta perspectiva nos interesa para pensar la imaginación no sólo como vinculada al recuerdo y al pasado, sino en su potencialidad creativa y productora de nuevas representaciones y conocimientos significativos para los sujetos.

\section{Las fotografías exteriores}

El recorrido del EMS comienza por fuera del sitio en el que estaba emplazado el edificio, que hoy se haya cubierto por un techo construido en el año 2010 bajo el que se encuentran, además las pasarelas.

Por fuera, se hallan dispuestos una serie de siete carteles en los que se exhiben fotografías del archivo de fotografías históricas. En ellas se muestran sectores de la antigua edificación de la Mansión Seré. Las imágenes están acompañadas por un croquis que indica el punto de vista respecto de la mansión en que la fotografía fue realizada, el año en que fueron producidas y por un pequeño epígrafe que las describe y/o aporta información sobre su fuente (Figura $\mathrm{N}^{\circ} 4$ ). Ordenadas cronológicamente, se presenta una fotografía de 1930, una de 1980, una de 1983, tres de 1984 y una de 1985. Por otro lado, sólo en tres de los epígrafes se indica el origen de la fotografía, mientras que el resto del conjunto no aporta esta información.

FIGURA No 4

Fotografías: Registro de campo 28-9-16

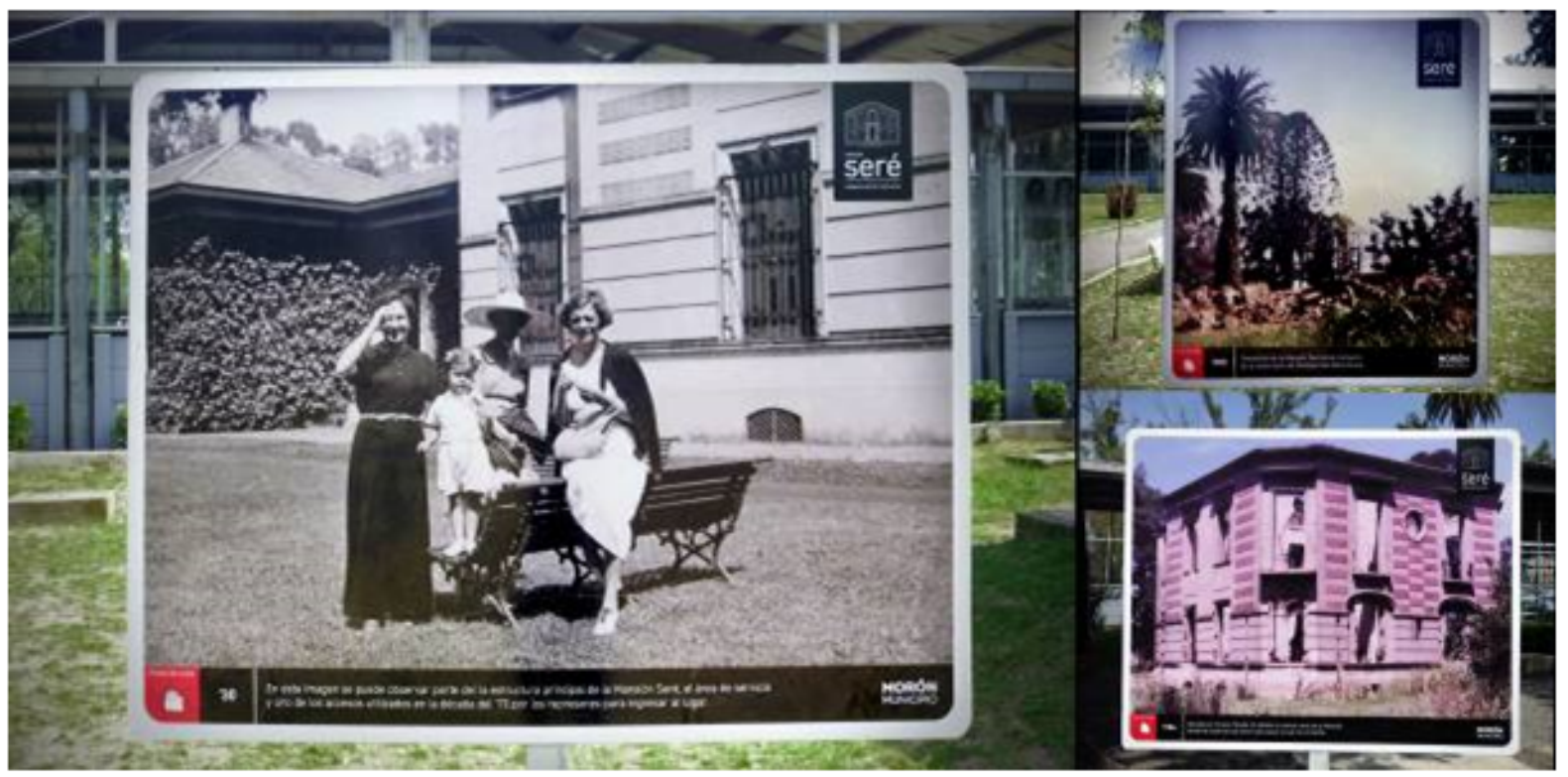


Los carteles están dispuestos alrededor del sitio arqueológico de manera tal que el visitante se sitúa en el punto de perspectiva desde el que se ha realizado la toma fotográfica (Figura $\mathrm{N}^{\circ} 5$ ). Es decir, la disposición de estas imágenes alrededor del EMS nos ayuda a reconstruir la escena de la realización de cada fotografía y nos propone situarnos en la posición del fotógrafo que hizo la imagen. De esta manera se produce un efecto particular propio de la fotografía, el de la evocación del pasado que nos interpela desde el presente, pero que se potencia y favorece mediante su instalación en el espacio y en los carteles como dispositivo. Estos últimos posibilitan un contraste visual inmediato entre la fotografía que portan y la imagen actual del EMS que permite que la huella del pasado que reside en cada fotografía se proyecte sobre la ausencia de la Mansión que la perspectiva actual revela. Como en el trabajo Ausencias de Gustavo Germano, es la falta del cuerpo lo que queda en evidencia, cobrando importancia lo que no puede verse (Fortuny, 2008). La fórmula de Barthes (1994) esto ha sido con la que describe la particularidad propia de la fotografía, es lo que se pone en juego en este dispositivo memorial por medio de la confrontación con el esto es. Al mismo tiempo, permite que el visitante proyecte la imagen fotográfica en el espacio y reconstruya cómo se vería el edificio desde ese punto de vista. De esta manera se propicia una acción del visitante, la de la reconstrucción imaginaria del edificio ausente.

Por otro lado, mediante la indicación del año de cada fotografía, se hace énfasis en la construcción de una cronología visual de la historia de la Mansión, conformando una serie en la que cada imagen y la imagen actual resignifica a las demás. La ausencia de la Mansión Seré es subrayada por la huella de las fotografías en que aparece en diferentes momentos de su historia. En esta cronología el recorte temporal es amplio, excede el CCD y narra la historia de la edificación desde sus primeros registros visuales en los años treinta hasta su demolición en el retorno de la democracia. Este agrupamiento en serie permite hacer una reconstrucción no sólo de los detalles edilicios de Mansión Seré sino también de una trayectoria temporal sobre los distintos usos y momentos de la misma, reconstrucción que es siempre fragmentaria e incompleta del mismo modo que el archivo con que se realiza. Esta fragmentariedad puede ser completada por la imagen que el visitante proyecta en el actual sector techado del espacio.

FIGURA N5

Fotografía: Registro de campo 28-9-16

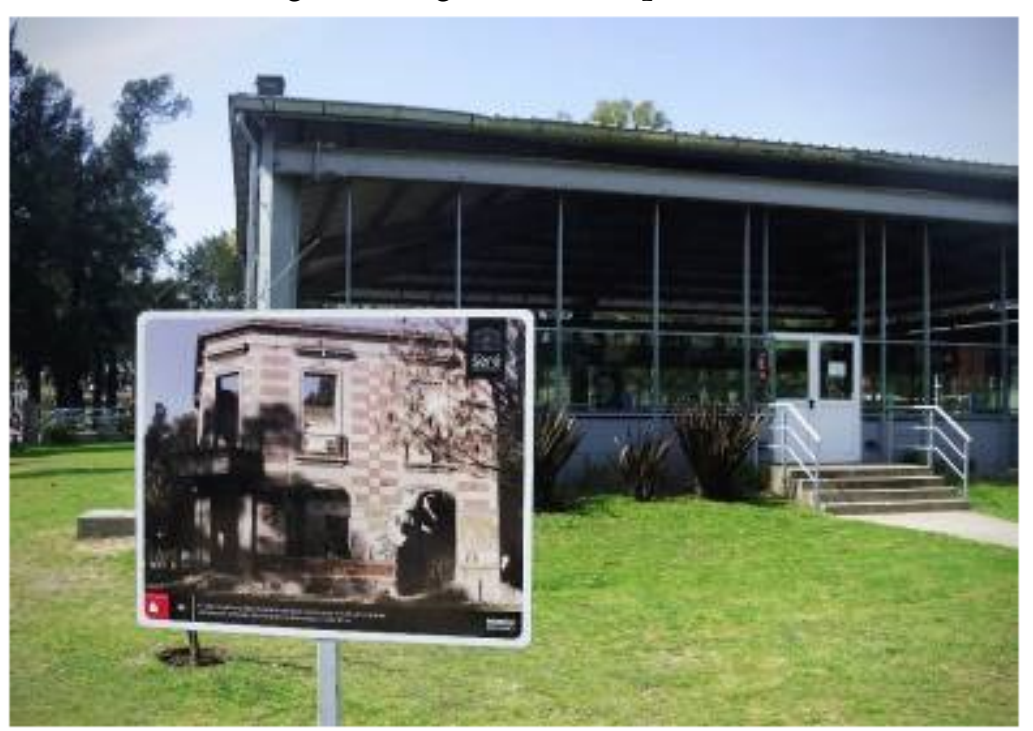




\section{Las vitrinas}

El recorrido permanente del sector techado del EMS cuenta con diecisiete paneles informativos y cinco vitrinas. Como representativa del grupo, tomaremos una de estas últimas en la que se exhiben alrededor de cincuenta carozos de durazno dispersos junto al siguiente texto (Figura $\mathrm{N}^{\circ} 6$ ):

Entre los hallazgos arqueológicos hubo una notable concentración de carozos de durazno.

Fragmento del relato de un sobreviviente en el cual hace referencia a la conversación que mantuvo él con uno de los represores luego de una sesión de tortura:

'...pero tengo sed, me estoy muriendo de sed', pero yo agua no te puedo dar, si te doy agua te vas a morir de un infarto, pero tomá, comete dos duraznos que el durazno no te va a hacer nada, eso, quédate tranquilo, el durazno comélo...' (Osvaldo Sánchez. Dirección de DDHH del Municipio de Morón, 2006)

Registro de campo 26-04-14

\section{FIGURA $\mathrm{N}^{\circ} 6$}

Vitrina A. Fotografía: Registro de campo 26-04-14

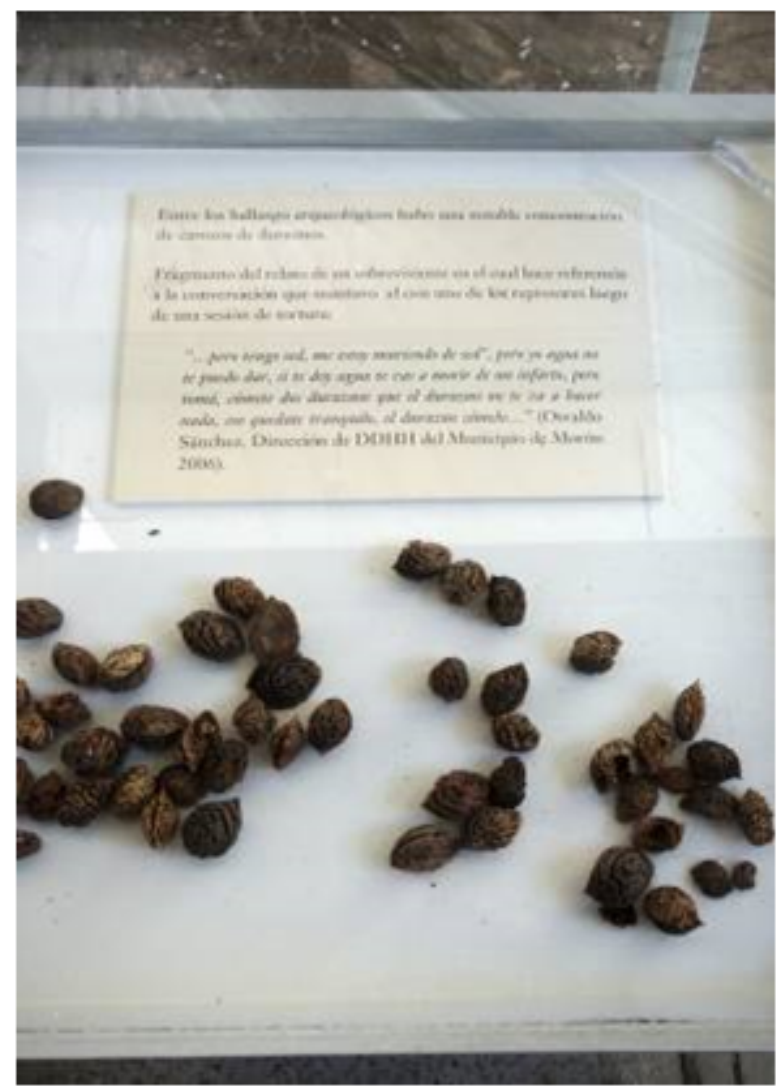

Podemos reconocer que el contenido de la vitrina se compone de tres elementos: el registro arqueológico (el conjunto de carozos), el testimonio de Osvaldo Sánchez en su propia voz y una segunda voz anónima que presenta y describe a los elementos anteriores.

La vitrina opera de modo indicial, el observador no accede por medio de lo expuesto a la escena de la tortura ni a sus métodos, no hay un relato explícito de ello, pero sí se muestran sus huellas, los restos de carozos y el diálogo posterior a la tortura. Esta estrategia de representación requiere de una operación por parte del observador en la que re-construya el sentido de lo expuesto. La misma se basa en las tramas que habilitan el Archivo Documental y los hallazgos arqueológicos, que permiten poner en diálogo sus diferentes materiales. Mediante estos diálogos se privilegian ciertos sentidos de cada material sobre otros, como en el caso de los 
carozos de durazno, que, como refiere uno de los investigadores, no solamente remiten a la tortura en "Atila" sino a los usos de la Quinta Seré:

(...) porque antiguamente en este predio, cuando la familia Seré estaba, era un lugar que tenía un montón de árboles frutales, entonces de algo como un carozo vos podés contar varias cosas: podés contar para qué los Seré tenían este lugar y que hubo testimonios que hablaban de que a algunos les daban una fruta para no darles agua porque si no se morían después de la tortura, digo, podés hablar de varias cosas. ${ }^{16}$

De este modo, en las vitrinas se activan sentidos memoriales sobre los materiales arqueológicos, las pruebas científicas comienzan a vehiculizar recuerdos sobre la historia del lugar y el terrorismo de Estado.

Este tipo de tratamiento y representación se distancia diametralmente del show del horror (Feld, 2014) que hegemonizó la representación del terrorismo de Estado durante fines de los ' 80 y' 90 . En este caso si bien algunos de los testimonios orales expuestos se refieren a algunas prácticas represivas del centro clandestino, la orientación de los mismos no es la de detallar las situaciones, contextos y prácticas de la represión para una sociedad civil que pretende "saberlo todo", no son testimonios que den cuenta de una posición de victimasino que están orientados a dialogar con los objetos materiales que los acompañan. De esta manera los testimonios no son sólo de sobrevivientes ni se enfocan únicamente en la descripción de las prácticas represivas:

Vitrina b): “...todas las piezas tenían piso de madera, y el pasillo, el baño y la cocina tenían baldosas, baldosas con dibujitos, esas baldosas viejas con motivos. No sé si era todo con motivos o si había...no recuerdo exactamente pero sé que había baldosas con motivos ¿no? (Fernández op. Cit.)

“...Se ve desde el hueco de la escalera piso de baldosas cuadradas pequeñas, de fondo blanco (sucio) con guardas" (Alejandra Tadei ante la CONADEP 1984)

Vitrina c): "venían los cirujas con carritos, masa y cortafierro a llevarse todo...hierros, caños, rejas. Yo no iba a ser menos... con un destornillador me llevé los manijones y rejas de la puerta (...) quería llevarme las tejas pero cuando fui ya estaban todas rotas...me querías llevar algunas cerámicas de la chimenea porque eran hermosas...” (Luis com.pers.2009)

“...Después del incendio cuando la casa estaba en ruinas, me llevé una teja porque sabía lo que había pasado allí...La tenía barnizada y colgada en el patio de mi casa”. (Anónimo com.pers.2003).

Vitrina d): “...piso de madera, pared pintada totalmente ya desvencijada, con ventana cancel, tenían la típica ventana de hierro y ventana de vidrio...Era el piso de madera, listones de pinotea largos...Se escuchaban fuerte los ruidos de la escalera. Cuando se escuchaban los ruidos de la escalera o era que era la patota que venía a torturar o era que venía la patota con algún detenido..." (Nora Etchenique. Dirección de DDHH del Municipio de Morón 2005)

“...Sentías esas escalinatas bom, bom, bom... una patota, no sólo yo sino que los demás compañeros ya estábamos con temor a que sabíamos que donde se abría una puerta éramos golpeados.” (Osvaldo Sánchez. Dirección de DDHH del Municipio de Morón 2006)

“El incendio de la Mansión fue el 24 de junio del '78, el día de la Fogata de San Juan, que es el día de la Caza de brujas..." (Laura con.pers.2006)

Registro de campo 26-04-14

Orientados de este modo, el diálogo entre los testimonios orales y los objetos materiales produce un efecto de verdad $^{17}$ sobre la existencia física de la Mansión, sobre sus detalles edilicios y materiales de construcción y sobre sus usos a partir de una ligazón indiscutible. De esta manera las vitrinas nos cuentan la historia de Mansión Seré mediante las pruebas de que ello ha ocurrido. Lo expuesto en ellas son algunas de las conclusiones de la investigación arqueo-antropológica y de este modo se narra no sólo la historia del lugar sino el proceso de investigación científica.

Al tiempo que se inauguraba en 2013 el espacio, se estaban llevando a cabo juicios por crímenes de lesahumanidad en los que el Municipio de Morón participó como testigo, en parte, con la información obtenida de la investigación arqueo-antropológica de Mansión Seré. Existe así una simultaneidad en la que, mientras se desarrollan los juicios, se exhiben pruebas en el recorrido del EMS. Acorde con otra etapa de elaboración de políticas de la memoria, en el EMS no hay un tratamiento que apele al Show del Horror, sino que adecuado a su contexto, presenta pruebas del funcionamiento del CCD "Atila". 
Besse y Messina (2015) proponen pensar en testimonios coalescentes como un entramado de testimonios que a priori no tienen unidad pero que mediante una soldadura, la coalescencia, se produce un efecto de verdad. De esta manera "la verdad histórica se constituye en el entramado y no en cada uno de los testimonios" (Besse Y Messina, 2015:622) sin perder de vista que los testimonios implican la articulación de enunciados y contextos de enunciación. En este sentido, propongo pensar la vitrina antes descripta como un dispositivo mediante el que el testimonio y memorias de sobrevivientes y vecinos y los datos arqueológicos coalescen (Besse y Messina, 2015) produciendo un efecto de verdad sobre el funcionamiento del CCD. En este caso ese efecto de verdad reside en la constatación de la existencia de Mansión Seré, así como de la tortura en "Atila” y la cotidianeidad del centro. Además, las vitrinas en tanto dispositivo memorial resaltan otra característica de esta coalescencia:

La coalescencia, insistimos, tiene que ver, entonces, con cómo se suelda lo que a priori no tiene una unidad. Y cómo ese entramado testimonial participa de una estrategia de transmisión intergeneracional, es decir de una inscripción social de ese acontecimiento, que trascienda el campo de los expertos, que lo coloque en un escenario social más amplio. (Besse Y Messina, 2015:622)

Ana Guglielmucci analiza para los casos de ex ESMA y ex "Olimpo" a los gestores de esos espacios como actores que proponen el pacto tácito a sus visitantes de aceptar que las marcas edilicias y los objetos arqueológicos hallados son huellas del pasado equivalentes a las interpretaciones que se hacen de ellas: "la presentación de marcas edilicias y los objetos arqueológicos en términos de "testimonio" o "recuerdo vivido", supone al visitante aceptar el "como si" en términos de lo que "realmente fue y ya no es" (Guglielmucci, 2013:295) En relación a esto, nuestra hipótesis es que en las vitrinas del EMS no existe ese pacto tácito sino que lo que se intenta es demostrar al visitante la veracidad del relato histórico que se hace de Mansión Seré a través de la presentación de las pruebas con que ese relato fue re-construido. Las vitrinas presentan las conclusiones de la investigación propiciando que ellas sean formuladas por los visitantes, acercándoles el proceso de la investigación y activando la coalescencia entre sus datos. Esta estrategia, además, posibilita que el efecto de verdad suscitado esquive la formulación de un relato unificado, de significación plena, ya que deja expuestas las lagunas propias del trabajo de investigación que sigue siempre abierto a la incorporación de nuevas materialidades, datos e imágenes sobre el pasado, de modo que no permite relatos conclusivos con sentidos estables.

De esta manera, las pruebas judiciales presentadas en los juicios por crímenes de lesa-humanidad en la denominada "subzona 16" son presentadas también en el EMS a un público general más amplio que no conoce en profundidad la historia del lugar y que no se reduce al conjunto de expertos científicos y especialistas.

\section{Algunas COnClusiones}

El análisis comenzado sobre las estrategias de representación del Espacio Mansión Seré se inscribe en el debate sobre la representabilidad/irrepresentabilidad y lo decible/indecible acerca del horror de las catástrofes sociales a la hora de recordar y de transmitir el pasado. En relación a lo planteado por Regine Robin respecto del Holocausto, creemos que las dos estrategias del recorrido del EMS analizadas pueden ser pensadas como un intento de representación distinta, como dos formas de transmisión que intentan no saturar la memoria. Esta idea se relaciona con lo que proponen Croccia, Guglielmucci y Mendizábal (2009) para el patrimonio hostil, lo que implica una forma de activación de la memoria sobre el pasado que inhabilita un relato cerrado y unificado, ya que hace referencia a contradicciones y tensiones del pasado histórico que nos interpelan e incomodan. El patrimonio hostil trae al presente imágenes, escenas, vivencias y discursos que lejos de presentar un pasado cristalizado y eterno, aspiran a la creación de subjetividades desde una labor pedagógica que se proyecta en la construcción de un futuro próspero motorizado por la acción humana (Guglielmucci, 2010; Croccia, Guglielmucci y Mendizábal, 2008). Es de esta manera que la 
huella cobra importancia en los dispositivos memoriales del EMS. La disposición de los objetos, testimonios y fotografías en tanto huellas del pasado en el recorrido por el espacio propicia que los visitantes realicen una re-construcción de ese pasado, acercándose al trabajo arqueológico realizado allí. Como en toda arqueología, sólo se poseen fragmentos, piezas que van aportando a la construcción de un mosaico interminable, un archivo siempre abierto. Es a partir de la laguna del archivo, su naturaleza agujereada y las huellas del pasado que nos provee que se pone en movimiento la imaginación sobre los sucesos pasados. "Para saber hay que imaginarse" dice Didi-Huberman (2004) y en el caso de Mansión Seré la imaginación aparece como uno de los modos para acercarnos a su historia: un trozo de madera junto al relato de un sobreviviente sobre las pisadas de la patota (el "bombombom") dispara la creación de imágenes multisensoriales sobre esa escena del pasado, nos permite imaginarnos cómo fue. Siguiendo a Ileana Dieguez (2013) también es posible pensar que estos testimonios funcionan sinecdóquicamente, permitiendo "mover el pensamiento en imágenes" para entender el ilimitado ejercicio del horror. Al mismo tiempo, esta escena imaginada nos incomoda, nos obliga a situarnos en una violencia pasada que es perturbadora y que nos corre de la indiferencia. Es entonces que los baches del archivo, lo fragmentario de las memorias y los testimonios se tornan espacios y resquicios donde se suscita la imaginación. Las fotografías dispuestas alrededor del EMS invitan a imaginar cómo fue la Mansión allí emplazada en determinada época y todos los rincones y detalles que el recorte inacabado de las fotografías no nos muestran. En este punto se hace pertinente la pregunta que se hace Ricoeur: "¿no se habla de recuerdo-imagen, incluso del recuerdo como de una imagen que uno se hace del pasado?" La coalescencia es el yeso de ese mosaico interminable, que como el archivo y la investigación arqueológica, están abiertos a nuevos testimonios y memorias, fragmentos que se van incorporando al relato sobre la historia de Mansión Seré.

Si bien la imaginación es orientada y modelada por los dispositivos memoriales en cuanto a cómo y con qué elementos interpretar el pasado, es la potencialidad que ella tiene en su dimensión creativa la que puede permitir que los sentidos del pasado no se cierren ni unifiquen. Esto está dado por las características propias de la presencia/ausencia de materialidad con que los dispositivos operan. En una etnografía sobre la experiencia de quienes visitan sitios de memoria en Chile, Montenegro, Piper, Fernández y Sepúlveda afirman que relatos construidos sobre los objetos y los lugares no siempre son estables porque:

habitados de presencias y ausencias movilizan mundos subterráneos de la imaginación de sus visitantes, haciendo emerger otras significaciones capaces de declinar temporalmente la codificación prevista, y de este modo, posibilitando otras narrativas alojadas temporalmente en los intersticios de lo real-ficcional (Montenegro et alt, 2015:1732).

La política de memoria del EMS puede ser vista como la autora de un relato oficial e institucional sobre la historia del lugar que intenta incluir las memorias no sólo de familiares y sobrevivientes del terrorismo de Estado sino también las memorias del barrio Seré y sus vecinos, a partir del aporte de sus testimonios (orales, objetuales y/o fotográficos) para la reconstrucción histórica de Mansión Seré. La producción de este relato implica una serie de disputas, decisiones y negociaciones que involucran ya no sólo a los gestores e investigadores del EMS sino a un conjunto amplio de actores que incluye militantes de derechos humanos, otros agentes estatales y vecinos. De este modo, el trabajo arqueo-antropológico y el recorrido del EMS contribuyen a contar una parte de la dictadura pero de una manera anclada y enmarcada en memorias barriales.

Los dispositivos analizados podrían ser pensados como un punto de partida para la construcción de estrategias de transmisión del pasado que eviten una representación plena, clausuradora de sentidos y que habiliten espacios para la generación de representaciones propias que contribuyan en el conocimiento y la comprensión del pasado. Como plantea Robin (2014), quizás este tipo de búsqueda sea la indicada para que la memoria sobre el pasado no se sature de imágenes cristalizadas. 


\section{Bibliografía}

Achiam, M. (2016). “The role of imagination in museum visits”. Nordisk Museologi. Nro 1 Pp. 89-100

Agamben, G. (2011). “¿Qué es un dispositivo?”. Revista Sociológica. Nro 73, pp. $249-264$

Barthes, R. (1994). La cámara lúcida. Nota sobre la fotografía. Barcelona: Paidós.

Besse, J. y Messina, L. (2015) "Testimonios coalescentes: emergencias de la razón militante en las narrativas sobre la fuga del centro clandestino de detención Atila/Mansión Seré”. Kamchatka Revista de análisis cultural. Número especial: Avatares del testimonio en América Latina. P. 613-632

Calveiro, P. (2005). Poder y desaparición: los campos de concentración en Argentina. Buenos Aires: Colihue. Croccia,

M., Guglielmucci, A. y Mendizabal, M. E. (2009). "La recuperación de ex centros clandestinos de detención, tortura y exterminio en la ciudad de buenos aires: entre el patrimonio hostil y los edificios fetiche” en BOIVIN, Mauricio y otros. Politica, instituciones y gobierno: abordajes y perspectivas antropológicas sobre el hacer politica. Buenos aires: Antropofagia.

Deleuze, G. (1990). “¿Qué es un dispositivo?” En: Deleuze, G.; Glucksmann, A.; Frank, M. \& Balbier, E. Michel Foucault, filósofo. Gedisa, Barcelona, pp. 155-163

Didi-Huberman, G. (2007). "Cuando las imágenes tocan lo real”. Cuando las imágenes tocan lo real. Madrid: Arte y Estética. (pp. 7-36)

Didi-Huberman, G. (2004). Imágenes pese a todo. Memoria visual del Holocausto, Barcelona: Paidós.

Diéguez, I. (2013). Cuerpos sin duelo. Iconografias y teatralidades del dolor. Argentina: A/E Ediciones DocumentA/Escénicas.

Di Vruno, A.; Diana, A.; Seldes, V.; De Haro, M. T.; Doval, J.; Giorno, P. y; Vázquez, L. 2006). “Arqueología en ( un centro clandestino de detención. El caso Mansión Seré -Atila." En: Libro de resúmenes del $3^{\circ}$ Congreso de Arqueología Histórica: Facultad de Humanidades y Artes, Rosario. P. 61-62.

D'ottavio, A. (2017). Si algo es capaz de decir, de si mismo o de algo, algo: intervenciones expertas sobre las materialidades de los ex centros clandestinos de detención, tortura y exterminio de la Ciudad de Buenos Aires. Tesis de maestría. Universidad Nacional de San Martín. Instituto de Altos Estudios Sociales. Disponible en el Repositorio Institucional de la UNSAM (TMAG IDAES 2017 DAL): https://bit.ly/2CqdBf4 [Fecha de consulta:16/05/2019]

Doval, J.; Giorno, P. F.; De Haro, M. T. y; Diana, A. N. (2010). “Mansión Seré: una reconstrucción arquitectónica desde la imagen fotográfica”. En BERÓN y otros. Mamül Mapu: pasado y presente desde la arqueología pampeana. Ayacucho, Pcia. de Buenos Aires: Editorial Libros del Espinillo. P. 215-226.

Doval, J. y Giorno, P. F. (2010). “Análisis de los procesos de formación cultural en el sitio Mansión Seré. Un abordaje a partir del proceso destructivo de la casona (1978-1985)". La Zaranda de Ideas. Revista de Jóvenes Investigadores en Arqueologia. Nro.6. P.37-55.

Doval, J. (2011). Cultura material, fotografias y memoria oral en la construcción del espacio social. El caso Mansión Seré. Tesis de Licenciatura, Facultad de Filosofía y Letras, Departamento de Ciencias Antropológicas, Universidad de Buenos Aires.

Fabri, S. (2010). "Reflexionar sobre los lugares de memoria: Los emplazamientos de memoria como marcas territoriales". Geograficando Nro.6 P. 101-118

Fabri, S. (2011). "Los lugares de la memoria en buenos aires. Mansión seré a diez años de su recuperación". GEOUSP - Espaço e Tempo. Nro. 29, P. 169 - 183.

Fabri, S. (2016). Procesos socioespaciales y prácticas memoriales. Espacialización, lugarización y territorialización en la recuperación del ex centro clandestino de detención "Mansión Seré" Tesis doctoral. Facultad de Filosofía y Letras, Universidad de Buenos Aires. 
Feld, C. (2014) "¿Hacer visible la desaparición?: las fotografías de detenidosdesaparecidos en el testimonio de Víctor Basterra", en Clepsidra. Revista Interdisciplinaria de Estudios sobre Memoria, Vol. 1, nro. 1, pp. 28-51.

Fortuny, N. (2008). "La foto que le falta al álbum. Memoria familiar, desaparición y reconstrucción fotográfica en la obra de dos artistas argentinos". En: XII Jornadas Nacionales de Investigadores en Comunicación. "Nuevos escenarios y lenguajes convergentes" Escuela de Comunicación Social - Facultad de Ciencia Política y RRII - 2008. Rosario

Foucault, M. (1990). La arqueología del saber. México: Siglo XXI

Gamarnik, C. (2015). "El rol del fotoperiodismo en la construcción de la democracia en Argentina (1983-2002)", L'Ordinaire des Amériques [En ligne], Nro. 219.p.1-24

Guglielmucci, A. (2013). La consagración de la memoria: una etnografía acerca de la institucionalización del recuerdo sobre los crimenes del terrorismo de Estado en la argentina. Buenos Aires: Antropofagia.

Montenegro, M.; Piper, I.; Fernández, R. y Sepúlveda, M.2015). “Experiencia y materialidad en lugares de memoria colectiva en Chile" Universitas Psychologica, Nro. 5 Vol.14, pp.1723-1734

Ricoeur, P. (2004). La memoria, La historia, el olvido. Buenos Aires: Fondo de Cultura Económica

Robín, R. (2014). "Sitios de memoria e intercambios de lugares" Clepsidra. Revista Interdisciplinaria de Estudios sobre Memoria. Vol. 1, nro. 2, pp. 122-145.

San Julián, D. (2014). “La construcción de un lugar de memoria en la Provincia de Buenos Aires. Mansión Seré, Morón, 1983-2007”. Trabajos y Comunicaciones, 2 da Época, nº 40, 2014.

Triquell, A. (2012). Fotografias e historias. La construcción narrativa de la memoria y la identidad en álbumes fotográficos familiares. Montevideo: Centro Municipal de Fotografía de Montevideo.

\section{Notas}

1 Un debate en profundidad respecto del lugar de las imágenes en la representación del Holocausto puede verse en DIDIHUBERMAN, G. (2004). Imágenes pese a todo. Memoria visual del Holocausto. Barcelona, Paidós. En esta obra, el autor hace una defensa de la importancia de la circulación de imágenes sobre el horror del Holocausto a partir del análisis de cuatro fotografías realizadas en Auschwitz por un Sonderkommando y discute con aquellos autores que creen que estas imágenes, por ser insuficientes, mienten al tratar de dar cuenta del horror, que es inimaginable.

2 El 24 de marzo de 1976 una junta militar liderada por Jorge Rafael Videla, Emilio Eduardo Massera y Orlando Ramón Agosti realizó un golpe militar apoyado por un sector de la población civil destituyendo de la presidencia a María Estela Martínez de Perón e iniciando el autodenominado “Proceso de Reorganización Nacional”. Esta dictadura cívico-militar se mantuvo hasta el 10 de diciembre de 1983 y se caracterizó por la censura, la vigilancia, la represión, el terror sistemático, el uso de la violencia, la detención clandestina, la tortura y exterminio de personas y el robo de bebés. Para un análisis sobre esta caracterización ver Pilar Calveiro (2005).

3 Nos referimos a los juicios por crímenes de lesa-humanidad en la denominada "subzona 16" en los que los integrantes del área de investigación y producción documental de la Dirección de DDHH de Morón declararon como testigos y donde la investigación arqueológica sirvió como línea de evidencia acerca del uso de la Mansión Seré como CCD. El primero de ellos se realizó durante el año 2008 y el segundo en el período 2014-2015.

4 Esta historización es tomada de FABRI, Silvina. (2010). Reflexionar sobre los lugares de memoria: Los emplazamientos de memoria como marcas territoriales. En: Geograficando 2010 6(6): 101-118- 183

5 Durante la presidencia de Néstor Kirchner iniciada en 2003, se intensificó en Argentina un proceso histórico abierto previamente en la construcción de la memoria oficial sobre la violencia política de los años '70. Parte de las políticas públicas propuestas en esta dirección se materializaron, entre otras, en la declaración de nulidad e inconstitucionalidad de las Leyes de Obediencia Debida y Punto Final, reabriéndose así las causas judiciales a los represores, el establecimiento del 24 de marzo como feriado nacional y la oficialización de diferentes Espacios para la Memoriaen sitios en los que durante la dictadura cívico-militar se cometieron delitos de lesa humanidad por parte del Estado argentino. Entre ellos, el predio conocido como la antigua Escuela de Mecánica de la Armada (E.S.M.A.), que funcionó como Centro Clandestino de Detención, Tortura y Exterminio, utilizado por el ejército nacional, fue transformado en el "Espacio Memoria y Derechos Humanos (Ex - E.S.M.A.)”. Para un análisis en profundidad ver Guglielmucci (2013). 
6 Para un análisis en profundidad del proceso de recuperación del Predio Quinta Seré como lugar de memoria ver Fabri 2016.

7 Municipalidad del Partido de Morón. Convenio N³4/02,27/03/2002. Archivo DD.HH. Morón n 173. Citado en San Julián, 2014.

8 San Julián (2014) describe y analiza una serie de tensiones entre los actores que intervinieron en la puesta en marcha del programa de memoria en el EMS, poniendo en relieve algunas contradicciones entre los intereses de cada uno.

9 Entrevista realizada en Morón el 04-06-2014.

10 Entrevista realizada en Morón el 04-06-2014.

11 La consulta sobre el contenido del archivo se realizó en junio de 2014.

12 Ver Fabri, Silvina. (2011). "Los lugares de la memoria en buenos aires. Mansión seré a diez años de su recuperación”. GEOUSP - Espaço e Tempo, São Paulo, No 29, pp. 169 - 183,

$13 \mathrm{La}$ CONADEP fue creada en 1983 mediante un decreto del entonces presidente Raúl Alfonsín para investigar las desapariciones cometidas durante la dictadura cívico-militar. Como señala San Julián (2014) en su informe publicado en 1984, titulado Nunca Más, fueron declarados 340 CCD localizados por la comisión entre los cuales se incluyó "Quinta de Seré" haciendo referencia a la Mansión Seré. El informe fue utilizado para la elaboración fiscal en el juicio realizado a las juntas militares que ocuparon el poder entre 1976 y 1982.

14 Una de las primeras imágenes Mansión Seré en la prensa puede encontrarse en Diario Clarín: “Localizaron otra cárcel clandestina” 17/10/1984.

15 La traducción es mía, del original: "I view imagination as the essential capacity that enables us to form a mental representation of something" y "Imagination is involved in the synthesis of new knowledge because it allows us to create mental constructions based on observation, existing knowledge, and what is not present".

16 Entrevista realizada en Morón el 04-06-2014.

17 Nos ubicamos en la propuesta de Foucault (1990) para pensar la noción de verdad como vinculada al saber de una época, que se instituye a partir de la proliferación de ciertos discursos que se convierten en visibles y enunciables socialmente y que son posibilitados por su situación en determinadas relaciones de poder de un cierto tiempo y lugar. 